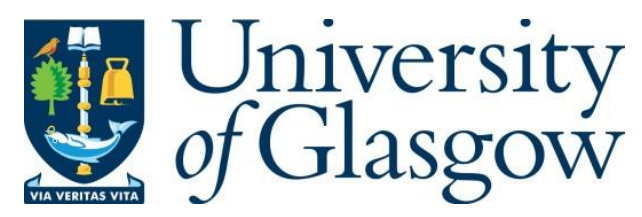

Metz, F., Leifeld, P. and Ingold, K. (2018) Interdependent policy instrument preferences: a two-mode network approach. Journal of Public Policy, (doi:10.1017/S0143814X18000181).

There may be differences between this version and the published version. You are advised to consult the publisher's version if you wish to cite from it.

http://eprints.gla.ac.uk/163631/

Deposited on: 01 August 2018

Enlighten - Research publications by members of the University of Glasgow http://eprints.gla.ac.uk 
This article has been published in a revised form in the Journal of Public Policy [http://doi.org/10.1017/S0143814X18000181]. This version is free to view and download for private research and study only. Not for re-distribution, re-sale or use in derivative works. (C) The authors.

\section{Interdependent Policy Instrument Preferences: A Two-Mode Network Approach}

\author{
Florence Metz ${ }^{1,2, *}$
}

Philip Leifeld ${ }^{3}$

Karin Ingold $2,4,5$

\footnotetext{
${ }^{1}$ Natural Resource Policy Group, Institute of Environmental Decisions, ETH Zürich, Zürich, Switzerland

${ }^{2}$ Institute of Political Science, University of Bern, Bern, Switzerland

${ }^{3}$ School of Social and Political Sciences, University of Glasgow, Glasgow, Scotland, United Kingdom

${ }^{4}$ Department of Environmental Social Sciences, Swiss Federal Institute of Aquatic Science and Technology (Eawag), Zürich, Switzerland

${ }^{5}$ Oeschger Centre for Climate Change Research, University of Bern, Bern, Switzerland

* Florence Metz, ETH-NARP, Swiss Federal Institute of Technology Zurich, Universitätstrasse 22, 8092 Zurich, + 41 (0)44 63388 68, florence.metz@usys.ethz.ch
}

\section{Acknowledgements}

The authors would like to thank the Swiss National Science Foundation for their generous support (Grant number CR21I1L_146336, 'CrossWater - Transboundary Micropollution Regulation in Europe: The Definition of Appropriate Management Scales - An Interdisciplinary Approach'; grant number 105217_140395, 'How to explain instrument selection in complex policy processes'; and grant number 149410, 'Overlapping Subsystems: Identification and Integration of Fragmented Games in Swiss Water Politics'). We are grateful for insightful comments by Hans Bressers and the members of the Policy Analysis and Environmental Governance group at University of Berne including Laurence Brandenberger, Laura Herzog, and Lorenz Kammermann. Three anonymous reviewers provided thoughtful inputs and helped to improve our paper. A previous version of this paper was presented at the European Conference on Social Networks, June 14-17 2016, Paris. We would like to thank conference discussants and panel members for their helpful thoughts on our paper.

Replication materials are available at https://doi.org/10.7910/DVN/SX7ESZ. 


\begin{abstract}
In policymaking, actors are likely to take the preferences of others into account when strategically positioning themselves. However, there is a lack of research that conceives of policy preferences as an interdependent system. In order to analyze interdependencies, we link actors to their policy preferences in water protection, which results in an actor-instrument network. As actors exhibit multiple preferences, a complex two-mode network between actors and policies emerges. We analyze whether actors exhibit interdependent preference profiles given shared policy objectives or social interactions among them. By fitting an exponential random graph model (ERGM) to the actor-instrument network, we find considerable clustering, meaning that actors tend to exhibit preferences for multiple policy instruments in common. Actors tend to exhibit interdependent policy preferences when they are interconnected, i.e., collaborate with each other. By contrast, actors are less likely to share policy preferences when a conflict line divides them.
\end{abstract}

Keywords: Policy instruments, policy instrument preferences, collaboration, policy networks, two-mode networks, exponential random graph models

\title{
Introduction
}

The paper analyzes policy preferences of political actors in order to better understand collective policy formulation. In democratic systems, policy decisions rely on majorities formed through negotiations in decision-making processes. To create such majorities in line with own preferences, actors have an incentive to convince others of their own policy preferences. Similar policy preferences are thus an outcome of strategic positioning in a power game to create majorities. Actors may position themselves given others' preferences through the exchange of information (Leifeld and Schneider 2012) or mutual learning about advantages and disadvantages of various policy options (Weible et al. 2010; Crona and Parker 2012). Thereby actors create common interpretations or reasoning and influence the policy preferences of those they have been in contact with before.

Despite potential interdependencies between collective actors, there is a lack of research that conceives of policy preferences as an interdependent system. To address this research gap, we study mechanisms behind the formation of policy preferences of collective actors and take into account their interdependent choices. We analyze whether actors' policy preferences are partly conditional on other actors' choices, thereby forming a complex, interdependent system of preferences. More specifically, we ask: which joint properties lead actors to adopt similar policy preferences in the actor-instrument network?

The "actor-instrument network" refers to our conceptualization of actors and their policy preferences as a two-mode network, where policy actors represent the first mode and policy preferences the second mode (for a similar approach see studies on the support/veto of legislative bills by members of parliament, see Zhang et al. (2008), Harward and Moffett (2010), Briatte (2016)). We conceptualize policy preferences as support for, or rejection of, specific policy instruments. Policy instruments (e.g., bans, charges, information campaigns) are single means through which defined policy goals can be reached (Lasswell 1958). Collective actors are organizations that participate in policymaking processes, including state-actors with formally assigned regulatory competences, and non-state actors who contribute to the design or 
implementation of policies (Schneider 2014). A tie between an actor and a policy instrument indicates a preference (support or rejection) for that instrument by the actor. A complex twomode actor-instrument network emerges as actors exhibit multiple preferences, and multiple actors can prefer the same policy instrument.

To better understand the mechanisms driving this interdependent system of preferences, we employ a model that specifically accounts for interdependencies of observations, called Exponential Random Graph Model (ERGM) or p* model (Robins, Pattison, et al. 2007, Robins, Snijders, et al. 2007, Wasserman and Pattison 1996) Cranmer et al. 2017). The use of a network approach over dyadic logistic regression is necessary to model the dependencies between observations and avoid a resulting omitted variable bias because the actors possess mutual relevance and visibility in their instrument choices (Cranmer et al. 2017). While there exists a solid number of studies using ERGMs on one-mode data, fewer applications exist in the field of two-mode networks (but see Jasny 2012; Berardo 2014; Jasny and Lubell 2015). One contribution of this paper is to introduce non-standard endogenous model terms for the analysis of two-mode network data. Such methodological advances provide us with new tools to address the classic question of social theory about how behavior (in our case policy preferences) is affected by social relations (Granovetter 1985, Marsden 1981).

The theoretical contribution of this paper consists of disentangling the different mechanisms that may lead actors to select the same policy. Bressers and O'Toole $(1998,2005)$ highlight two important aspects of social settings that can influence the choice of instruments in the process of policy formulation. They term the first mechanism "cohesion", which is about similarity in actors' policy objectives that frame their choices for policy instruments (see also Jenkins-Smith et al. 2014). For example, actors who exhibit the goal to protect the environment can be assumed to also share similar policy preferences. The second mechanism captures a relational dimension of policymaking and is called "interconnectedness". Accordingly, actors who are linked by some sort of interaction in the policy process are more likely to develop similar policy preferences. "Interaction" is a generic term for any type of social relation, which in the case of policymaking involves, for example, information exchange, negotiations, or collaboration between policy actors. The distinction between similar objectives and interactions as two mechanisms influencing preference formation is a puzzling question, from a methodological and theoretical perspective.

\section{Theory}

The study of policymaking integrates different levels of analysis as one has to consider both the policy preferences on the individual actor level and their aggregate on the collective-level. How individual-level preferences are translated into collective decisions is a matter of scholarly debate. Actor-level approaches focus on micro-level explanations of policymaking. They claim that actors have intrinsic interests that guide their behavior or policy preferences (Olson (1965). Group-level approaches shift attention away from individual actors to networks of relationships and claim social foundations of policy preferences (Marsden 1981). A network approach is not only an aggregation of policy actors' attributes, but it also takes into consideration actors' interdependencies (Sandström and Carlsson 2008, Lubell et al. 2012). We explore the dialectical relationship between micro-level and meso-level foundations of preference formation by, first, considering actors' joint attributes in form of policy objectives and, secondly, actors' interactions in form of direct collaboration. 


\section{Interdependencies of policy preferences}

Policymaking can be defined as the process during which actors work towards a) an agreement upon political goals and $b$ ) the selection of (appropriate) instruments to reach the defined goals (Howlett 2009, Landry and Varone 2005). It is not solely the work of authorities or single actors, but policymaking happens in a complex and intertwined setting that includes various public and private collective entities who aim to transform their preferences into public policy through their participation in the policymaking process (Knill and Tosun 2012, p. 41). The increased interest in network-like constellations of policymaking comes along with the recognition that, in most cases, no organization of government possesses sufficient authority, resources, and knowledge to enact and achieve policy intentions (Sabatier and Jenkins-Smith 1993). Instead, policies require the concerted effort of multiple governmental and societal actors (Bressers, O'Toole, and Richardson 1995, p. 4). In the study of environmental politics, the network approach is particularly relevant because pollution reduction requires the coordinated action of various sectors and levels across political boundaries. Thus, a networked policy subsystem is best approached through a network lens (Bressers, Huitema, and Kuks 1995, p. 7), which in our case involves a network of actors and their instrument preferences.

The network approach represents a shift of focus away from the policy instruments themselves (and their effects) to the actors participating in the process. Bressers and O'Toole (1998) expect that network characteristics influence instrument selection (Majone 1976). This argumentation is in line with the "logic of appropriateness" according to which actors (involved in policymaking) tend to reproduce existing features of the social system, i.e., formal and informal power structures, roles, and institutions, through their policy choices (Sager 2009, March and Olsen 1989). This logic can best be studied by conceptualizing the policy process as a network, and by linking network features such as actors' attribute similarity in terms of common objectives and their social relations to the choice of policy instruments. Bressers and O'Toole (1998) employ the term "cohesion" to refer to similar policy objectives that bring actors together or divide them in policy negotiations. With "interconnectedness", Bressers and O'Toole highlight the relational patterns linking state and non-state actors, or elected authorities, and target groups. With strong similarity of objectives and high interconnectedness among network members, a wide range of policy instruments is possible as long as they keep the social system intact. Our contribution is to disentangle the two elements, policy objectives and interconnectedness, and to study their individual significance for policy preferences. Thereby, we seek to achieve a fine-grained understanding of the socio-political context in which policy instruments are selected.

\section{Policy objectives}

Key to understanding policymaking in general, and policy instrument selection in particular, is to consider the behavior of those actors involved in formulating policies (Bressers and O'Toole 2005). A central element guiding political actors' behavior is their policy objectives, i.e., the goals they seek to transform into public policy in order to achieve their desired societal changes. In their work, Bressers and O'Toole distinguish situations in which actors share objectives from those situations where actors exhibit conflictive objectives. Additionally, they describe a third type of situation where actors' objectives are not shared, but nevertheless compatible and mutually reinforcing. In policy processes where diverse types of actors participate, it is likely to find a distribution of objectives-from conflictive over mutually reinforcing to shared. In order to describe the overall level of similarity of objectives among actors participating in decision-making, Bressers and O'Toole employ the term "cohesion" (Bressers and O'Toole 1998). A high level of network cohesion describes a situation where network members, i.e., those actors who participate 
in policymaking, share similar objectives. Cohesion, in turn, increases the probability of concerted instrument preferences.

Other branches of the literature have tried to explain in more detail what drives actors to share or diverge on policy objectives. One explanation is that actors involved in policymaking relate to the world through a set of perceptual filters that supports them in articulating policy objectives (Munro et al. 2002, Munro and Ditto 1997). These filters are termed "beliefs" in the terminology of the Advocacy Coalition Framework (ACF) (Sabatier 1999); other scholars refer to "mental models" (Pahl-Wostl 2007) or "macroculture", defined as norms and values shared across actors (Jones, Hesterley, and Borgatti 1997, Robins, Bates, and Pattison 2011). Such deeply rooted values or worldviews guide actors' preferences in the more instrumental decisions of matching policy goals with the instruments to achieve those goals.

Based on these theoretical underpinnings, we expect that actors relate to a similar set of policy instruments because they exhibit shared or mutually reinforcing objectives. Such shared instrument preferences are irrespective of coordination between actors, but are rather a result of a similar attribute, i.e., shared objectives in our case. Our hypothesis as depicted in Figure 1 reads as follows:

$H 1$ (policy objectives hypothesis): The more similar actors' objectives are, the more likely they exhibit preferences for a similar set of policy instruments.

\section{Interconnectedness}

Network scholars like Marsden (1981) or Granovetter (1992, 1985) drew attention to social dependencies, where actors' attitudes are influenced by the attitudes of their social environment. In a similar vein, policy actors are elements of social structures and therefore do not only individualistically form instrument preferences, but rather socially. Interactions among network members are likely to socially influence actors' attitudes, perceptions, behavior, and policy preferences. From this perspective, not only actors' attributes (e.g., objectives) need to be understood in order to explain policy preferences, but also actors' ties and their embeddedness in their social environment.

Particular to the political realm is that the structure of social relations reflects both formal hierarchy and informal bargaining processes. The logic of actors' interactions is framed by macropolitical institutions, which define formal decision-making power, or participation mechanisms (Howlett and Ramesh 1995, Weible and Sabatier 2005, Varone 1998). However, the structure of policy networks does not only reflect the formal setup of the political (sub)system, but also informal aspects of policymaking. Informal aspects matter for network structures, because policy negotiations also involve actors without formal decision-making power participating in policy negotiations (Lubell et al. 2012, Börzel 1998). Actors without formal decision-making power, such as non-state actors from the science community or interest groups, can participate, for example, in the pre-parliamentary phase of policymaking processes.

In the political realm, the structure of social relations matters to better understand how actors form their policy preferences. Actors create a social fabric in policymaking processes by initiating connections, e.g., by collaborating. As such connections among actors entail crucial information about social structure, the literature elaborates on several indicators of interconnectedness: the degree of inclusion of actors in policymaking processes (Ingold 2014, Ingold, Varone, and Stokman 2013), the quality of ties between authorities and target groups (Linder and Peters 1989, Varone 1998), or the degree of conflict between opposing coalitions (Weible, Pattison, and 
Sabatier 2010). Mutual relations among actors, such as collaboration or reciprocal information exchange, can create a common understanding of the policymaking process (Henry 2011; Leifeld and Schneider 2012; Fischer and Sciarini 2016). Actor' joint understanding of a situation, in turn, can lead to concerted policy preferences of actors in a policy subsystem. Studies also demonstrate that interconnectedness establishes trust and social capital, which can further enhance the creation of joint policy preferences (see Berardo and Scholz 2010). In this line of thought, we hypothesize as depicted in Figure 1:

H2 (interconnectedness hypothesis): Actors who interact with each other tend to exhibit a preference for similar policy instruments.

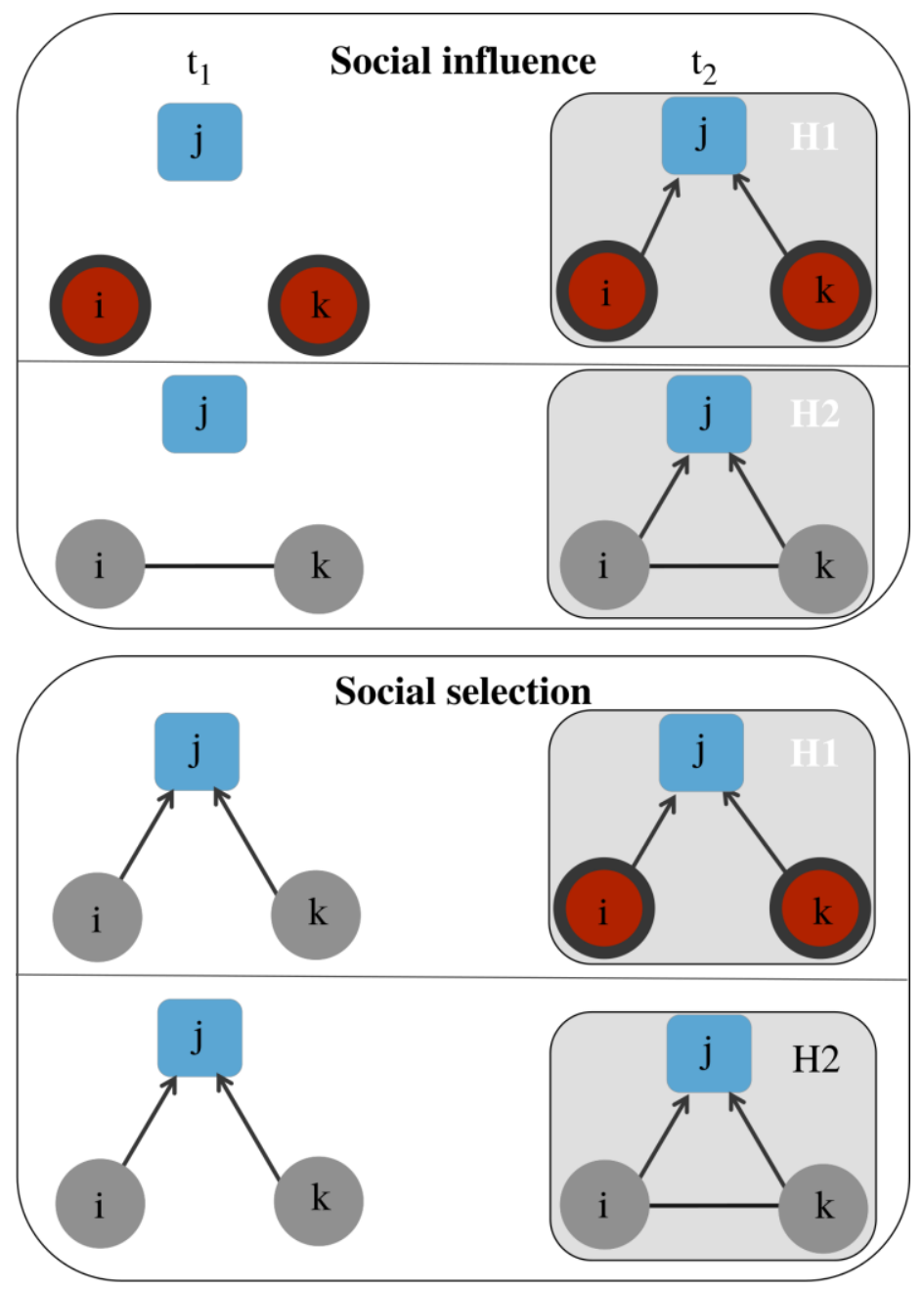

Legend:

$i, k=$ actors; $j=$ policy instrument

$\mathrm{H} 1=$ Hypothesis $1 ; \mathrm{H} 2=$ Hypothesis 2

$t_{1}=$ time $1 ; t_{2}=$ time 2

edge between $i$ and $k=$ interaction

arrow between $i$ and $j$ or $k$ and $j=$ preference

Figure 1: Schematic representation of Hypotheses 1 and 2.

Note: Hypothesis 1 on common objectives: two actors (circles) with same objective (red/black circle attribute) prefer the same policy instrument (square). Hypothesis 2 on interconnectedness: two actors (circles) interact (tie between actors) and prefer the same policy instrument (square). In this article, we do not horizontally distinguish selection and influence mechanisms, but rather vertically between hypotheses. 
In summary, we observe the local topology (i.e., a structure of nodes and ties) of preference interdependencies as defined by three elements: actors' attributes (objectives in our case), direct actor-actor interactions, and actors' policy instrument preferences. We analyze whether actors exhibit similar instrument preferences given, on the one hand, mutual policy objectives and, on the other hand, direct actor-actor interactions. In hypothesis 1, we study whether the topology of preference interdependencies is paralleled by similar attributes of actors, namely their objectives, independently of coordination between actors. For example, two environmental organizations may both exhibit the objective to promote water protection and, therefore, support the instrument "effluent charge". Despite their mutual objective, these actors do not necessarily coordinate their actions. Even without any transmission or exchange among actors, preference similarity exists. Similar policy preferences are consequently not a result of imitation or learning between actors in this mechanism, but rather an assortative mixing pattern (Newman 2002), where environmental organizations simply tend to support certain instruments, such as effluent charges. In hypothesis 2 , on the other hand, we analyze situations where actors do interact directly and jointly support policy instruments.

Our hypotheses are compatible with two causal mechanisms: social influence and social selection, which are generally confounded in observational studies of social networks (Shalizi and Thomas 2011). Social influence (also known as diffusion or contagion; see also Gilardi 2016, Lindstädt et al. 2017) posits that actors share attributes (H1) or collaborate (H2) first and then align their policy preferences in the two-mode network (see temporal pattern $t_{1}$ and $t_{2}$ in Figure 1). Selection (also known as homophily) ${ }^{1}$ posits that actors have congruent policy instrument preferences in the two-mode network first and develop shared attributes (H1) or collaboration ties (H2) as a consequence. Malang et al. (2017) demonstrate using a causal inference approach with temporal permutations that a causal identification strategy in this situation is only feasible if the timing of policy instrument preferences is measurable in a temporally fine-grained way on a nearly continuous time scale, which is next to impossible to implement for organizations' policy instrument preferences. In this paper, we do not distinguish between social influence and selection effects in networks (as for example in Malang, Brandenberger, and Leifeld (2017)). We rather describe instrument preferences as an interdependent system given attribute similarity (common objectives) or direct ties (interactions) in order to discriminate between the specific patterns in the actor-instrument networks as shown by $\mathrm{H} 1$ and $\mathrm{H} 2$ in Figure 1. In Figure 1, we focus on the dark shaded actor-instrument networks, which either describe $\mathrm{H} 1 \mathrm{or} \mathrm{H} 2$, but we do not incorporate the temporal dimension between $t_{1}$ and $t_{2}$, i.e., between left and right panels of Figure 1.

\section{Case and data}

Although our research question regarding the formation of policy preferences is relevant across policy domains, our study concentrates on environmental policy. The interplay between different types of actors is particularly relevant in environmental governance where diverse claims regarding the use and the protection of natural resources have to be balanced in policymaking. The integration of various stakeholders into environmental decision-making is often not a normative claim anymore, but an observable reality, namely through the establishment of collaborative governance structures (Newig and Fritsch 2009, Lubell and Fulton 2007, Bodin 2009, Ostrom, Cox, and Schlager 2014, Bodin and Prell 2011, Fischer and Leifeld 2015). Environmental

1 Both social selection and attribute similarity are compatible with the term ,homophily“, because homophily refers to a pattern not a causal mechanism. 
policy is therefore particularly well suited to analyze interplays between policy actors and the degree to which their exchanges affect the formulation of policy preferences.

More specifically, we take the case of water protection policy in Switzerland where there is growing policy attention to what are called "micropollutants" or "emerging pollutants", a large quantity of diverse chemicals that have only recently been detected and deemed a concern in water bodies due to improvements in analytical measurement technology (Schwarzenbach et al. 2006). Sources of such micropollution include, for example, the use of pharmaceuticals, personal care products, detergents, biocides, or plant protection products (Hollender, Singer, and McArdell 2008). Due to the large number of substances, sources, and entry-paths into the aquatic environment, it is a complex task to develop a pertinent policy response for the issue of micropollutants in water bodies and to choose among the many policy alternatives that exist. It is an ideal case to study policy preferences as the issue is rather new on the political agenda, and different actors involved in policymaking debate about a large variety of instruments that could potentially be introduced (Metz and Ingold 2014).

Switzerland is a pioneer in this emerging policy domain, since the issue entered the political agenda in the early 2000s and concrete measures have been debated since then. The present study examines the amendment process of the Swiss Waters Protection Act and Ordinance that took place between 2007 and 2014, during which Swiss policy actors negotiated about how to best address micropollutants from point sources of pollution, i.e., from household wastewaters. From April to July 2013, we surveyed state and non-state collective actors, who participated and have a stake in this policy process on micropollutants, including governmental bodies, science, political parties, water, environmental, and economic associations. We surveyed policy actors when they a) participated at least twice in the process of amending the Waters Protection Act and Ordinance (decisional approach), or b) hold formal regulatory competences in the domain of emerging water pollutants (positional approach, or c) were considered important by knowledgeable experts in the field (reputational approach) (Laumann, Marsden, and Prensky 1983, Knoke 1994). 32 actors (or 31 as one actor exhibits missing data on the objectives variable) replied to the relevant survey questions (see Figure 2 for the precise composition of the actor sample and Online Appendix 1 for the list of actors).

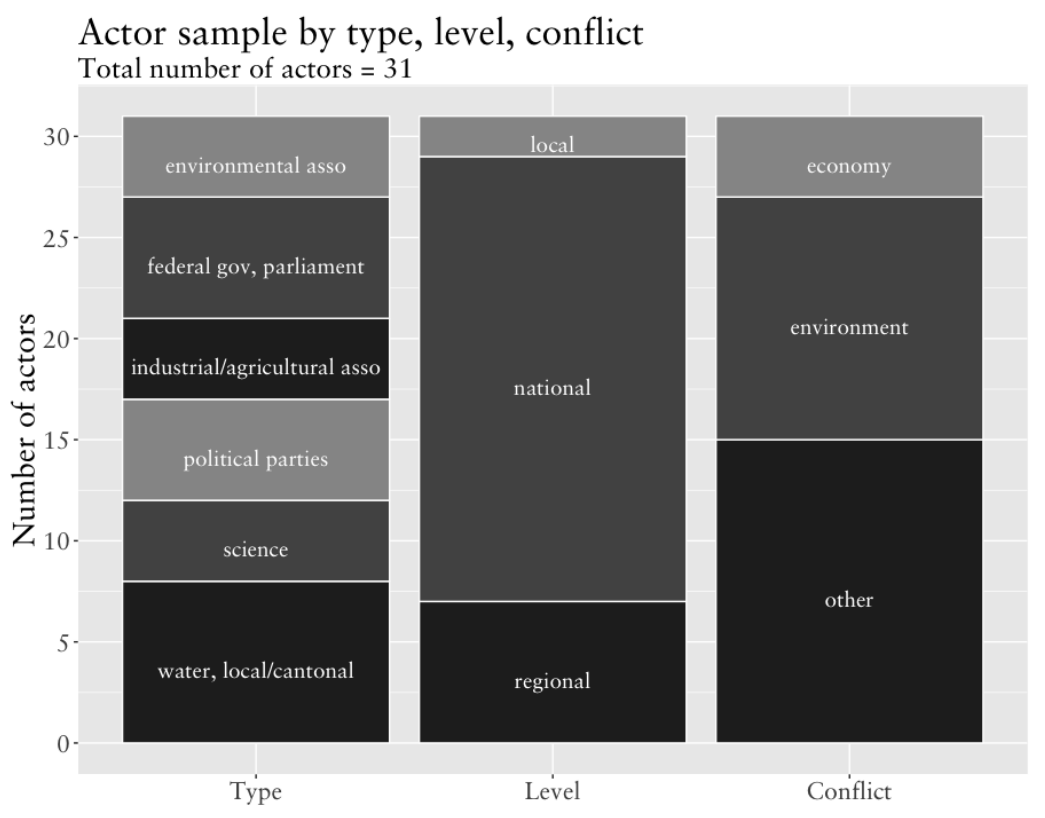

Figure 2: Actor sample by type, level and conflict, $\mathrm{n}=31$. 
We surveyed actors' preferences about 15 policy instruments for the reduction of micropollutants on a four-point Likert scale, where respondents could indicate from 1 to 4 whether they strongly disagreed (1), disagreed somewhat (2), agreed somewhat (3) or strongly agreed (4) with the policy instrument. Table 1 provides an overview about the 15 different regulatory, economic, and voluntary policy tools that were surveyed. We generated the list of instruments based on an inventory of instruments in water protection (Metz and Ingold 2014).

Table 1: Overview about surveyed instrument preferences.

\begin{tabular}{|c|c|c|}
\hline & Variable & Description of instrument \\
\hline \multirow[t]{3}{*}{$\begin{array}{l}\text { Regulatory } \\
\text { instruments }\end{array}$} & $\begin{array}{l}\text { userestr } \\
\text { disposal } \\
\text { bat }\end{array}$ & $\begin{array}{l}\text { Bans or authorization restrictions of single emerging pollutants } \\
\text { Use restrictions of single emerging pollutants } \\
\text { Discharge requirements for products containing harmful substances } \\
\text { Use of best available technique (BAT) for the elimination of } \\
\text { emerging pollutants (e.g., technically upgrading wastewater } \\
\text { treatment plants, treatment of wastewater partial flows in } \\
\text { companies or hospitals) }\end{array}$ \\
\hline & $\begin{array}{l}\text { bep } \\
\text { eqn }\end{array}$ & $\begin{array}{l}\text { Use of best environmental practice (BEP) for the reduction of } \\
\text { emerging pollutants inputs into waters } \\
\text { Establishment of environmental quality norms = immission limit for } \\
\text { relevant substances }\end{array}$ \\
\hline & el & $\begin{array}{l}\text { Definition of emission limits for selected pollutants } \\
\text { Control measures (e.g., expanding monitoring programs, obligatory } \\
\text { registries for emerging pollutants) }\end{array}$ \\
\hline $\begin{array}{l}\text { Market- } \\
\text { based } \\
\text { instruments }\end{array}$ & $\begin{array}{l}\text { pcharge } \\
\text { wwfee } \\
\text { subsi }\end{array}$ & $\begin{array}{l}\text { Increase of the wastewater charge to fund measures for the } \\
\text { reduction of emerging pollutants } \\
\text { Subsidies (e.g., for investments in filtering technology or monitoring } \\
\text { technology, optimization of production processes) }\end{array}$ \\
\hline \multirow[t]{2}{*}{$\begin{array}{l}\text { Information- } \\
\text { based } \\
\text { instruments }\end{array}$} & volunt & $\begin{array}{l}\text { Voluntary measures of companies and civil society (e.g., investments } \\
\text { in filtering technology, optimize production processes, labeling, } \\
\text { abdication) }\end{array}$ \\
\hline & $\begin{array}{l}\text { info } \\
\text { research } \\
\text { ppp }\end{array}$ & $\begin{array}{l}\text { Information campaigns, consulting } \\
\text { Research } \\
\text { Private-public partnerships, public-public partnerships }\end{array}$ \\
\hline
\end{tabular}

Figure 3 shows the two-mode networks of actors (circles) and their preferences towards the surveyed policy instruments (squares). The data reveals, in the overwhelming majority of cases, positive (agree somewhat) to very positive (strongly agree) results (see left part of Figure 3). Survey respondents agree with many different policy options in principle (see left part of Figure 3 ), while they have very specific ideas about what types of instruments they reject. The interesting variation thus occurs where respondents indicate that they disagree somewhat or 
disagree strongly with a policy instrument (see right part of Figure 3). This observation aligns with research focusing on opposition against policy instruments (see for example Kammermann and Dermont forthcoming). When actors oppose a specific policy instrument (mix), they can potentially block the entire decision-making process. As opposition is crucial to the choice of policy instruments (Keohane, Revesz, and Stavins 1998), we focus on policy preferences in the form of rejection rather than agreement. Rejection and support can be modeled interchangeably here because there is no neutral category such that "not rejecting" is equivalent to supporting.
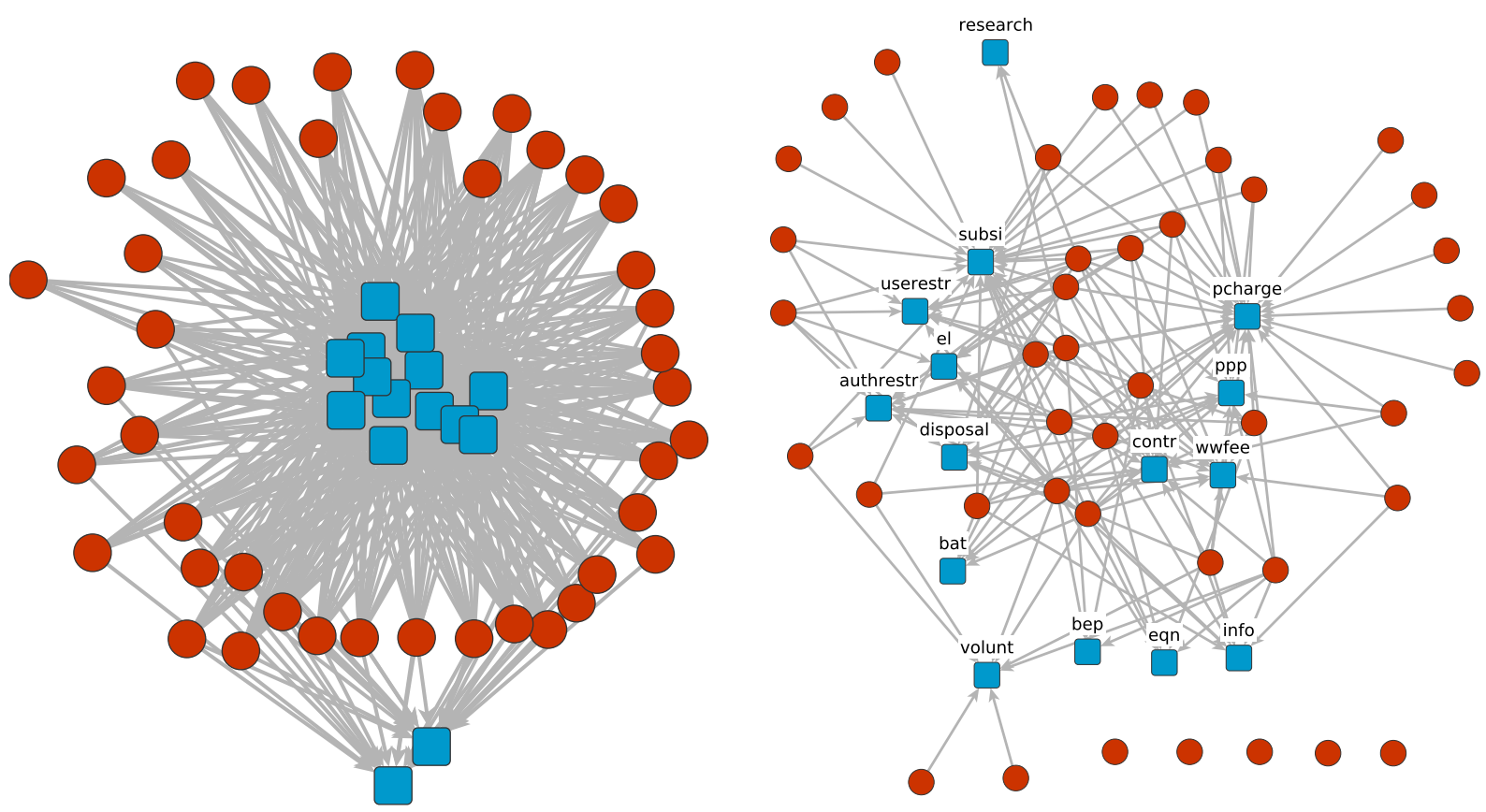

Figure 3: Two-mode network of policy instrument preferences.

Note: Support network ("agree somewhat" or "strongly agree") on the left; rejection network ("disagree somewhat" or "strongly disagree") on the right. Circles = actors, squares = policy instruments, ties = preferences in the form of support or rejection.

For our independent variables, the survey further included several questions capturing actors' objectives (H1) and their interconnectedness (H2). In water protection, actors can prioritize addressing the sources of pollution or the "end of the pipe". We elicited actors' objectives by asking respondents for their level of agreement, ranging from strongly agree (coded as 4) to strongly disagree (coded as 1 ), with the five following statements:

- Measures should address the sources of pollution.

- Measures should be end-of-pipe.

- Precautionary measures should be taken to reduce potential risks for humans and the environment (precautionary principle).

- It is reasonable to wait with policy measures until the impact of micropollutants is fully understood (risk-based principle).

- Policy measures should aim at completely eliminating micropollutants in waters.

Source-directed policy objectives reflect actors' goal to prevent the release of pollution into water in order to reduce human impact on the environment. End-of-pipe objectives, by contrast, focus on eliminating pollutants after their use and release into water and echo actors' priority in maintaining current consumption and production patterns. The precautionary principle stands for 
the goal to adopt policy measures despite existing uncertainties about adverse impacts of micropollutants on humans or the environment. The risk-based principle, by contrast, is in line with the objective that policy action is only needed where risks haven been proven. Finally, actors' objectives could diverge with regard to the level of pollution permitted (or admitted to be unavoidable) in water.

We further collected responses on actors' policy agenda priorities. Respondents were asked to rate the reduction of micropollutants as a higher priority, equal, or lower priority compared to 10 other water policy issues, i.e., (1) ecological status of water bodies, (2) classic "macropollution" such as nutrients/fertilizers, (3) industrial emissions, (4) wastewater treatment, (5) water levels, (6) ground water, (7) drinking water, (8) hydropower, (9) flood protection, (10) water monitoring.

Moreover, with the information about respondents' actor types (federal-state, political party, regional/water/local, environmental, industrial/agricultural, science), we classified them into two groups. The first group consists of water and green organizations, and the second one of industrial and agricultural organizations.

While the data described above serve as different proxies for policy objectives, the following data capture interconnectedness. We surveyed respondents' interconnectedness by asking them with whom their organization closely collaborated during the Swiss policy process on micropollutants between 2007 and 2013. Respondents could check all their collaborators from a list of actors that we previously identified by applying the positional, decisional, and reputational approach; respondents could add missing actors to the list. Close collaboration was defined as discussing new findings, developing policy options, exchanging positions, evaluating alternatives. Not only interactions with Swiss actors may be relevant, but also with international actors, e.g., during transboundary water basin meetings. We therefore asked respondents to report their memberships in international water basin organizations and then coded their co-memberships.

\section{Methodology}

We estimate a bipartite (=two-mode) exponential random graph model (ERGM) (Wasserman and Pattison 1996) to explain policy instrument preferences of actors. A two-mode network or bipartite graph is a network with two separate types of nodes that displays the connections (also known as ties) between the two node types. In our case, 32 policy actors comprise the first node type (or "mode"), and 15 policy instruments comprise the second mode. Ties in this network are the instrument choices actors make. Within-mode ties are not possible on the dependent variable because a bipartite graph is mathematically defined by between-mode ties. We chose a bipartite network model because the explanandum is the portfolios of instrument preferences the actors collectively hold, not the relations between actors or between preferences. For methodological details on bipartite ERGMs, see Wang et al. (2009). For applications to policy networks, see Berardo (2014) and Jasny and Lubell (2015). To accommodate the bipartite network structure, the normalizing constant of the ERGM was adjusted accordingly by the software we employed for estimation, the R package ergm (Hunter et al. 2008). Goodness of fit was assessed using the xergm package (Leifeld, Cranmer, and Desmarais 2017), and regression tables were created using the texreg package (Leifeld 2013).

The network we model is policy instrument rejection, as depicted on the right in Figure 3, while the reference group (the non-ties) contains all agreement ties depicted on the left in Figure 3. By modeling the sparser relation (rejection) instead of the denser complementary relation 
(agreement), we count fewer instances of endogenous network statistics such as two-stars and shared partners. This makes the model more easily identifiable without having to redefine the endogenous network statistics for the ERGM. However, since agreement ties are treated as the baseline in the model, this means only a conceptual, but not a substantive change.

The ERGM is a parametric model of the configuration of ties in a given network. Unlike a logistic regression model, the ERGM permits unbiased estimation of parameters for endogenous model terms that specify dependencies between observations (Cranmer and Desmarais 2011). It is important here to take into consideration that the profile of policy instrument preferences of one actor may depend, in part, on the preferences of another actor. We capture these dependencies by constructing respective model terms.

The probability density function of the ERGM is given by

$$
P(N, \boldsymbol{\theta})=\frac{\exp \left\{\boldsymbol{\theta}^{\mathrm{T}} \mathbf{h}(N)\right\}}{\sum_{N^{*} \in \mathcal{N}} \exp \left\{\boldsymbol{\theta}^{\mathrm{T}} \mathbf{h}\left(N^{*}\right)\right\}}
$$

where the $\boldsymbol{\theta}$ vector denotes the parameters of the model terms, the $\mathbf{h}$ vector contains the model terms, and the denominator represents the same sum of weighted statistics as the numerator, over all the network configurations one could have observed (Cranmer and Desmarais 2011, Cranmer et al. 2017). In the analysis, our task is to specify the exogenous and endogenous effects, or $h$ statistics, that contribute to the topology, or structure, of the network.

These network statistics are conveniently specified as sums of subgraph products (see Cranmer et al. 2017 for details). For example, the number of 2-stars found in the network can be defined as the sum of the product of local configurations $N_{i j}$ and $N_{k j}$, where $N_{i j}$ equals 1 if there is a tie from actor $i$ to instrument $j$ and 0 otherwise, and $N_{k j}$ equals 1 if there is a tie from actor $k$ to instrument $j$ and 0 otherwise. Estimation was carried out through Markov Chain Monte Carlo Maximum Likelihood Estimation (MCMC-MLE) (Hunter et al. 2008). Online Appendix 2 contains details about the estimation as well as robustness checks and alternative model specifications.

\section{Model terms}

We first introduce the model terms for our independent variables, then for the controls. Our two main variables, policy objectives and interconnectedness, can be operationalized in different ways. For the purpose of clarity, we therefore distinguish three versions of hypotheses 1 and 2, which in fact capture the same theoretical concept with slight nuances regarding measurement.

These model terms are conceptualized as bipartite homophily terms of the following form:

$$
h_{\text {homophily }}=\sum_{i} \sum_{j} \sum_{k \neq i}\left(N_{i j} N_{k j} f(i, k, X)\right)
$$

where $f(i, k, X)$ is some function of an exogenous actor covariate, which is stored in a square $m \times$ $m$ matrix $X$, and actor indices $i$ and $k$. We call this a "homophily" term because this model term tests whether a common property, such as a shared attribute or a collaboration tie, contributes to the probability that both actors $i$ and $k$ choose to have ties to the same instrument $j$.

More technically, this term counts instances of open triangles where both actors $i$ and $k$ are jointly connected to the same policy instrument $j$ through rejection ties, weighted by some shared or joint characteristic as expressed through a function of the exogenous covariate. For example, 
this model term could be used to count how often two actors who collaborate or who have some shared property jointly reject policy instruments. In other words, this statistic captures the tendency of actors to co-reject or co-support policy instrument preferences when they share certain characteristics, which will be detailed below.

\section{H 1a: Policy objectives}

The first measure of attribute similarity is operationalized through our data on policy objectives. Those objectives frame the more specific instrument preferences held by actors (Bressers and O'Toole 1998, Sabatier 1999). Let X be a $32 \times 5$ matrix with the row actors' policy objectives on a Likert scale from 1 to 4 .

The similarity in environmental policy objectives between actors $i$ and $k$ is defined as the inverse Euclidean distance (i.e., proximity) between rows in the policy objective matrix:

$$
f_{\text {objectives }}(i, k, X)=\frac{1}{\sqrt{\sum_{l}\left(X_{i l}-X_{k l}\right)^{2}}}
$$

where $l$ is the column index of the policy objective matrix and points to a specific objective. In

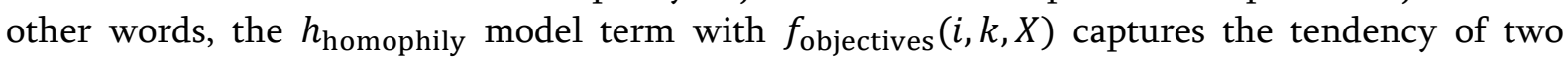
actors $i$ and $k$ with shared objectives to co-reject the same policy instruments.

\section{H 1 b (Policy objectives): Agenda priorities}

Actors differ in terms of the importance they ascribe to the micropollution problem relative to other issues related to water, such as the issues of flood prevention or hydropower. We identified ten issues including (1) ecological status of water bodies, (2) classic "macropollution" such as nutrients/fertilizers, (3) industrial emissions, (4) wastewater treatment, (5) water levels, (6) ground water, (7) drinking water, (8) hydropower, (9) flood protection, (10) water monitoring. We then measured actors' judgments of each issue's importance relative to micropollution ( $1=$ more important than micropollution; 0 = equally important; -1 = less important). Each actor has a priority profile over these issues, with one of these three objectives for each issue. This yields a $32 \times 10$ issue prioritization (or "agenda") matrix $A$.

The question we would like to answer with regard to issue prioritization is whether two actors who evaluate the issue of micropollutants as similarly important compared to other water policy issues tend to prefer similar policy instruments. This is accomplished by counting the number of two-stars centered on instrument $j$ weighted by the similarity of priority profiles of actors $i$ and $k$ involved in the $k$-star. This corresponds to the following function, which is identical to the previous $f_{\text {objectives }}(i, k, X)$ function with a new covariate matrix $A$ for the actors' issue prioritization or agendas:

$$
f_{\text {issue-prioritization }}(i, k, A)=\frac{1}{\sqrt{\sum_{l}\left(A_{i l}-A_{k l}\right)^{2}}}
$$

In other words, we compute the inverse of the Euclidean distance of any two row actors in terms of their issue prioritizations and weight any actor-instrument-actor two-path in the rejection graph by the similarity term.

\section{H 1c (Policy objectives): Conflict}

We also test whether material interest conflicts lead to diverging evaluations of policy instruments. We accomplish this by defining an explicit conflict line that we expect to be present 
in the data: if actor $i$ is a water association or environmental association and actor $k$ is an industrial or agricultural association, we expect conflicting opinions on how micropollution should be regulated. To do this, we insert the following function into the bipartite homophily model term defined above. The term captures the tendency of the network to have actor pairs with jointly present rejection ties to an instrument and who have conflicting organizational types:

$$
\begin{aligned}
& f_{\text {org-type-conflict }}(i, k, x) \\
& \quad=\left[x_{i}=\text { industry/agriculture }\right] \cdot\left[x_{k}=\text { environment/water }\right] \\
& +\left[x_{i}=\text { environment/water }\right] \cdot\left[x_{k}=\text { industry/agriculture }\right]
\end{aligned}
$$

where $x$ denotes a vector of categorical actor types and square brackets are an indicator function that returns 1 if true and 0 otherwise.

We expect a negative coefficient for this model term as the presence of a conflicting actor type configuration should lead to less co-rejection of instruments than in non-conflicting actor type configurations.

The conflict hypothesis is strongly related to Hypothesis 1a on congruence of objectives. But rather than measuring congruence of objectives or conflict at a more abstract level of values or norms, Hypothesis 1c evaluates how strongly the similarity of objectives matters in terms of the functional roles actors take.

\section{H 2a (Interconnectedness): Collaboration}

Let $C$ be a $32 \times 32$ binary matrix indicating collaboration between actors $i$ and $k$. Then including

$$
f_{\text {collaboration }}(i, k, C)=C_{i k}
$$

in a bipartite homophily model term measures the tendency of actors to reject instruments that other actors with whom they maintain collaboration ties also reject. In other words, this term tests whether actors' interconnectedness, operationalized through the maintenance of collaboration ties, is associated with similar policy preferences.

The paper is about a bipartite, or two-mode, network of actors and instrument preferences as defined in the homophily statistic above. Here, we employ a one-mode network matrix $C$ in the construction of the bipartite model term. Theoretically, this tests whether one-mode collaborations are associated with similar policy instrument preferences in the two-mode network.

\section{H $2 b$ (Interconnectedness): Structural similarity in the collaboration network}

If $C$ denotes the $32 \times 32$ binary collaboration network matrix, a structural similarity matrix can be computed as follows:

$$
Z=C C^{\top}
$$

This matrix denotes how many collaboration partners two actors have in common. It is a measure of similarity in collaboration interactions, and more specifically, in terms of the structural position in the network. Structural similarity in the collaboration network tests whether actors with an overlap in their collaboration profiles are more likely than chance would predict to co-reject the same policy instruments:

$$
f_{\text {collaboration-structsim }}(i, k, Z)=Z_{i k}
$$


This is a valuable alternative conceptualization of interconnectedness because interconnectedness may not only pan out directly through collaboration ties, but may equally plausibly occur through joint neighborhoods in the collaboration network. Joint exposure to common collaboration partners may spark the adoption of similar policy instrument preferences (or vice-versa).

\section{H 2c (Interconnectedness): Co-membership in water basin organizations}

Not only direct and indirect collaboration, but also mutual memberships in international water basin organizations can be an indicator of regular contact and interactions between two actors. When actors are members of the same water basin organization or platform, this significantly increases their chance of regularly exchanging information on policy preferences (Leifeld and Schneider 2012; Fischer and Leifeld 2015). Let $B$ be a $32 \times 2$ binary matrix indicating collaboration between actors $i$ and international collaboration partners $l$. Then we are interested in whether the co-occurrence network $B B^{\top}$ exerts any influence on the policy instrument preferences of actors. In other words, is an actor likely to reject (support) an instrument if there are many other actors who also reject (support) the same instrument with whom the focal actor shares international collaboration partners? This tendency is captured by inserting the following quantity into the bipartite homophily model term:

$$
f_{\text {water-body }}(i, k, B)=\sum_{l} B_{i l} B_{k l}
$$

\section{Endogenous control: Edges}

The edges term counts the number of edges in the two-mode network. This can be interpreted like a constant in a generalized linear model and serves as a baseline for the probability of edges in any dyad in the network:

$$
h_{\text {edges }}=\sum_{i} \sum_{j} N_{i j}
$$

Including the edges term is necessary in any ERGM, because it controls for the baseline edge probability, in this case the general rate of policy instrument rejection (like the offset $\alpha$ in a linear regression model).

\section{Endogenous control: Actor degree 0}

Figure 3 (right panel) displays a number of actors that do not reject any policy instruments at all. This is an endogenous property of the network that distinguishes it from a random graph with the same number of nodes and edges. Therefore we need to control for the number of actors with degree 0 ("isolates") to avoid omitted variable bias due to an incomplete specification of the endogenous part of the data-generating process:

$$
h_{\text {isolates }}=\sum_{i}\left[\sum_{j} N_{i j}=0\right]
$$

\section{Endogenous control: Instrument two-stars}

Some policy instruments receive many rejection ties while others are almost universally accepted. A two-star effect centered on the second mode (policy instruments) tests whether one rejection of an instrument is related to another rejection of the same instrument or, in other words, whether there is a popularity effect at work in which rejections tend to cluster within instruments. This 
may be the case if some instruments are universally considered poor solutions, for example. The two-star effect is defined as follows:

$$
h_{\text {instrument-popularity }}=\sum_{i} \sum_{j} \sum_{k \neq i} N_{i j} N_{k j}
$$

Including this term as a control variable is also important to distinguish the bipartite homophily effects defined above from the mere popularity of certain policy instruments.

\section{Endogenous control: Geometrically weighted non-edgewise shared partners}

Finally, we control for geometrically weighted non-edgewise shared partners (GWNSP), a typical dependency term for capturing clustering in two-mode networks. This model term computes the tendency of the network to have open two-paths, and it discounts higher numbers of two-paths between the same nodes. A two-path can exist between actors (via one or more instruments) or between two instruments (via one or more actors). GWNSP counts how many such two-paths exist between any given within-mode dyad, computes the aggregated distribution over the whole network, and sums up the counts in a geometrically weighted way by down-weighting higher numbers of shared partners geometrically (here: with an alpha parameter of 2.0). The definition of GWNSP (following the exposition of Hunter 2007) is

$$
h_{\mathrm{GWNSP}}(\alpha)=e^{\alpha} \sum_{i=1}^{n-2}\left\{1-\left(1-e^{-\alpha}\right)^{i}\right\} E P_{i}(N)
$$

where $\alpha$ is the geometric decay parameter (chosen inductively by model fit), and $E P_{i}(N)$ is the number of dyads within the same mode that have exactly $i$ shared partners. This weighted count effectively controls for clustering in the network in the sense that actors share multiple corejections and instruments are co-rejected by multiple actors. Omitting this endogenous dependency would yield biased estimates of the main hypotheses because homophily terms may be statistically conflated with the general tendency for co-rejection of instruments if not modeled separately.

\section{Exogenous control variable: Degree centrality in the collaboration network}

The effects related to collaboration between actors can only be interpreted in a valid way if we control for the number of collaboration ties actors have in the first place (i.e., their activity). Therefore we also include the number of ties, or degree, of any actor:

$$
h_{\text {collaboration-degree }}=\sum_{i} \sum_{j}\left(N_{i j} \sum_{k} X_{i k}\right)
$$

\section{Exogenous control: Non-adjacent competence level}

Assume $g$ is a vector of ordinal-scaled competence levels of policy actors from 1 (national level) to 3 (local level).

This term tests whether actors at non-adjacent and non-identical levels (i.e., national and local) have less congruent policy instrument preferences:

$$
f_{\text {complevel-nonadjacent }}(i, k, g)=\left[\left|g_{i}-g_{k}\right|>1\right]
$$


The square brackets denote an indicator function, which returns 1 if the term inside the parentheses is true and 0 otherwise. In this case, the function returns 1 if the absolute distance between the competence levels is larger than 1, i.e., if one actor has a competence level of 1 (= national level) and the other one 3 (= local level). The function is inserted into a bipartite homophily model term defined above.

It is plausible that actors at the same level develop shared approaches to dealing with a problem. It is still somewhat plausible that actors of adjacent levels, i.e., local and regional or regional and national actors, influence each other's instrument choices somewhat, respectively. Therefore we control whether a spillover of instrument preferences is implausible in order to yield a clean test for the other hypotheses.

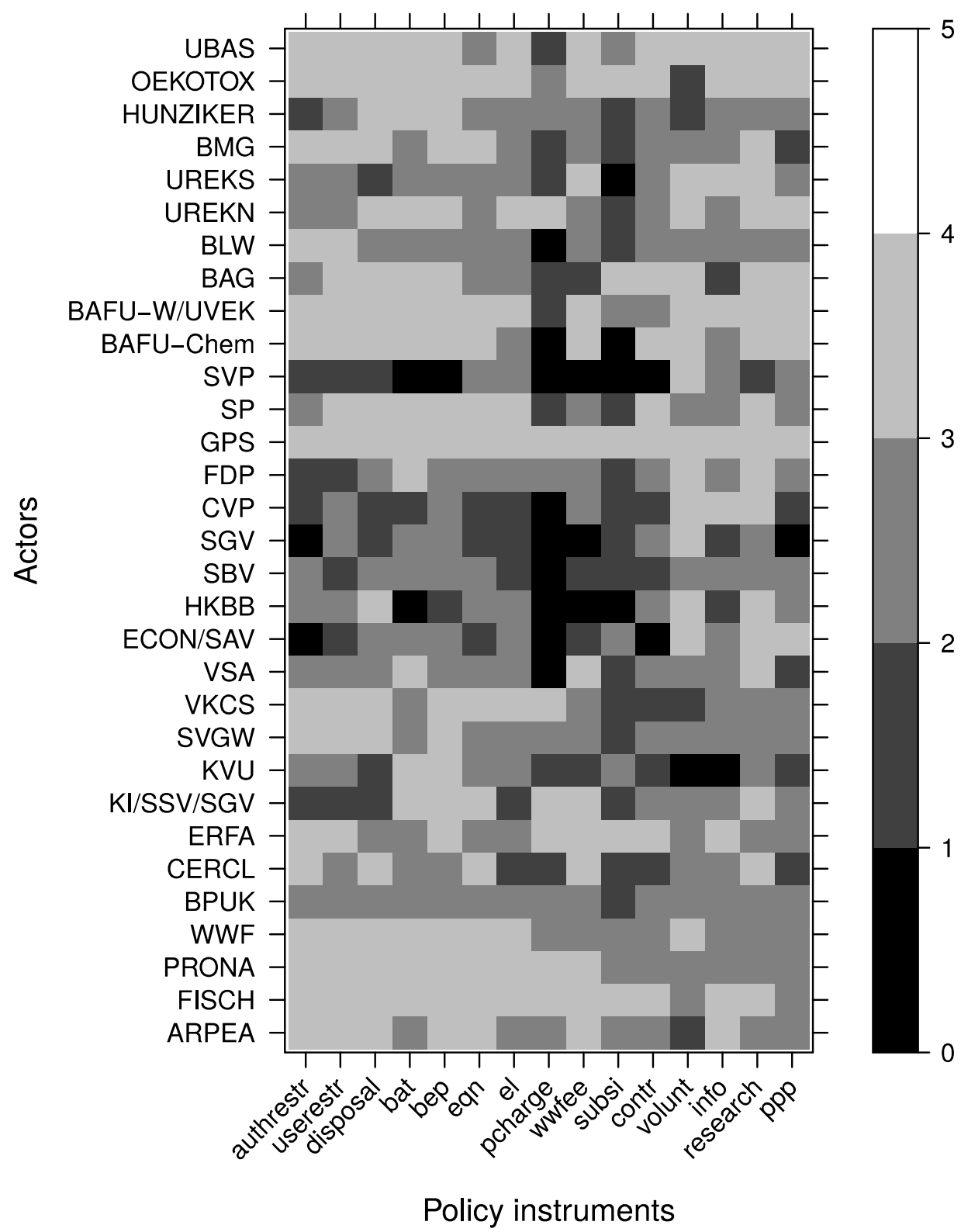

Figure 4: Instrument preferences for 15 policy instruments, from most coercive instruments on the left to least coercive instruments on the right (for an explanation of the surveyed policy instruments, see Table 1).

Note: squares in black and dark grey coded as 1 and $2=$ rejection, squares in light grey coded as 3 and $4=$ support; 31 surveyed actors are ordered by conflict line. Bottom = advocates of water protection (including: ARPEA to WWF = environmental associations, BPUK to VSA = water and local/cantonal), middle = advocates of economy (including: ECON/SAV to SGV = industry/agricultural associations, CVP and SVP = conservative parties), top = other (including: FDP to $\mathrm{SP}=$ political parties, BAFU-Chem to UREKS = federal government and parliament, BMG to UBAS = science). 


\section{Results}

Figure 4 illustrates which types of policy instruments received particularly high rejection rates (squares in black and dark grey coded as 1 and 2) and support (squares in light grey coded as 3 and 4). There are high levels of support with most types of policy interventions, which further illustrates that opposition towards policy instruments is the crucial point of negotiation rather than the support of instruments. Economic instruments (product charges, wastewater fees, subsidies) enjoy highest rejection rates, while most regulatory and voluntary instruments are far less controversial.

The actors in Figure 4 are ordered according to conflict lines. Actors who advocate water protection (from ARPEA to VSA) appearing in the bottom part of Figure 4 tend to support a variety of policy instruments with one exception: KVU, the Cantonal Offices for Environmental Protection, rejects voluntary instruments and information campaigns as too "soft". By contrast, actors who represent industrial and agricultural interests (from ECON/SAV to SGV and conservative parties such as SVP or CVP) reject a greater variety of policy instruments, in particular economic ones such as charges on products containing harmful substances or a wastewater fee.

We previously illustrated the distribution of instrument preferences and turn now, in Figure 5, to the patterns behind interdependencies of policy preferences. As the opposition towards one policy instrument may logically preclude the opposition for another, there may be a strong tendency for policy preferences to cluster. Figure 5 shows combinations of instrument preferences in form of co-rejection as computed by a hierarchical cluster analysis. There is no clear clustering pattern, apart from product charges and subsidies that actors tend to co-reject in common. Results indicate that preference formation is not a function of the popularity of certain instruments, but rather the result of more complex social processes.

Cluster Dendrogram

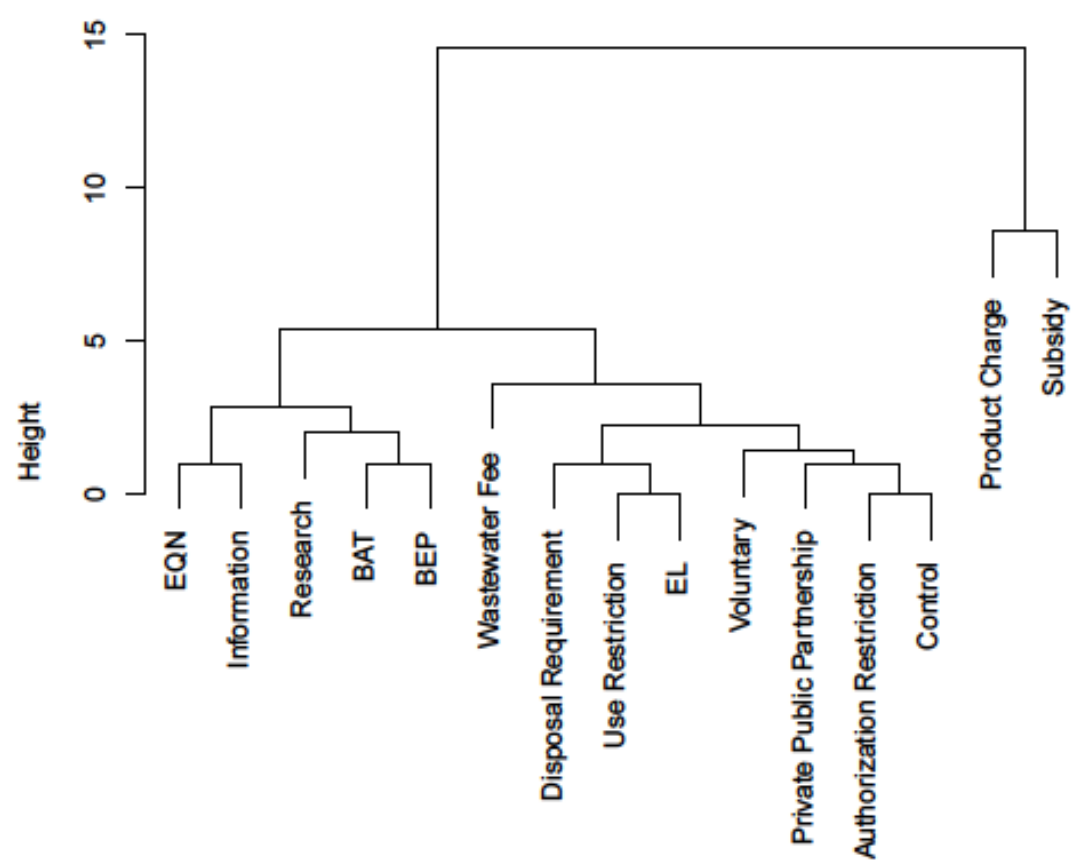

Figure 5: Preference profiles of actors' opposition (strongly disagree and disagree somewhat) towards 15 policy instruments, number of actors $=31$.

Note: Dendrogram based on an agglomerative hierarchical cluster analysis with complete linkage of Euclidean distances of the instrument $\times$ actor matrix. 
In order to understand the structure of preference interdependencies given common objectives or direct interactions, we estimated two models. The first model includes all hypotheses except for H1a ("policy objectives"). The second model includes all model terms. The reason is that to include H1a, it is necessary to drop one of the 32 actors because one actor exhibits missing data on this variable, and ERGMs can only be estimated if there are no missing data. The predictive (within-sample) performance, as indicated by the area under the receiver-operating characteristic curve (AUC-ROC) and the area under the precision-recall curve (AUC-PR), is identical in the two models, as are the substantive results.

The findings in Table 2 show that there are interdependencies between actors' policy preferences. We observe significant patterns for actors sharing multiple policy preferences (a positive effect for non-edgewise shared partners), meaning that actors tend to reject multiple policy instruments in common, rather than just one. Together with the negative two-stars coefficient, the results indicate that actors do not reject instruments independently of the preferences of other actors, but they rather tend to reject several policy instruments jointly. If an instrument is rejected by one actor, it tends to be rejected by other actors, too, but only if actors agree on rejecting several instruments jointly. There is thus a considerable social dimension in developing policy instrument preferences.

In order to explain this complex, interdependent system of preferences we analyzed actors' similarities in policy objectives. Our first operationalization of Hypothesis 1 on policy objectives does not yield any significant results. The same holds true for our second operationalization capturing agenda priorities that actors attribute to the issue of micropollutants. These results indicate that actors do not tend to align their preferences with others who are similar in terms of policy objectives or agenda priorities. By contrast, ideological conflict lines between water or environmental organizations, on the one hand, and industrial or agricultural organizations, on the other, systematically shape the topology of instrument preferences. In line with our expectations, actors who are divided by a conflict line are less likely to exhibit interdependent policy preferences. A conflict line between actors advocating the use of water resources and actors advocating the protection of it reduces their odds of co-rejecting policy instruments. Overall, we find mixed evidence for the policy objectives hypothesis. A conflict line divides actors along environmental and economic objectives. This conflict line is the only significant factor operationalizing hypothesis 1 that is associated with the co-rejection of policy instruments.

We find significant results for actors' interconnectedness in the form of collaboration ties. Whether actors collaborate with each other is significantly associated with their instrument preferences. In our case of water protection policy, actors collaborated, for example, within working groups that the Federal Office for the Environment initiated in the framework of its "Strategy Micropoll" as of 2007. Those groups were composed of diverse actors including cantons, operators of treatment plants, drinking water associations, science, and industry. Within those groups, actors discussed about the water issue at hand and exchanged their positions on policy options thereby creating common interpretations of the problem and solutions. The policy process provided further opportunities for collaboration during the elaboration of the draft legal revision, consultations, or parliamentary debates. In sum, actors who participated in the policy process had numerous occasions to collaborate and develop shared instrument preferences.

We do not only expect that collaboration induces shared instrument preferences (Figure 1, social influence, lower panel), but also that shared prior instrument preferences may lead to collaboration (Figure 1, social selection, lower panel). An actor is more likely to reject a policy instrument if the actor collaborates with a number of actors who also reject the same instrument, 
and two actors likely collaborate if they have shared policy instrument preferences. Our results further corroborate the hypothesis according to which collaboration and instrument preferences interrelate in policy networks (Zafonte and Sabatier 1998; Fischer and Sciarini 2016).

We also tested whether actors who occupy similar positions in the collaboration network - i.e., have the same shared contacts - (structural similarity) co-rejected the same instruments, but this is not the case. Indirect influence through shared collaborators does not play a role for the development of policy instrument preferences. Moreover, joint memberships in water basin organizations does not stimulate deliberation to the extent that shared memberships in these forums leads to shared policy instrument preferences, while controlling for actual collaboration between actors. Overall, there is support for the interconnectedness hypothesis, but only through direct collaboration, not through shared contacts or joint forum participation.

We also tested the three mechanisms within each hypothesis separately (see Models $2 \mathrm{~b}$ to $2 \mathrm{f}$ in Online Appendix 2) to avoid statistical problems with multicollinearity among predictors of the same theoretical category. Moreover, we tested one group of hypotheses at a time in a separate model specification to rule out multicollinearity between $\mathrm{H} 1$ and $\mathrm{H} 2$ (Model $2 \mathrm{~g}$ in Online Appendix 2). These modifications did not change the conclusions substantively, which indicates that these are indeed complementary hypotheses rather than substitutes.

Conceptualizing policy instrument preferences as a two-mode, rather than one-mode, network helps disentangling policy objectives from interconnectedness because modeling a one-mode projection of instrument preference similarity among actors would likely remove variation at the level of instruments that generates differences between policy objectives and interconnectedness. This more thorough approach therefore suggests that elements from both actors' objectives and their interconnectedness play a role in the interdependent structure of policy instrument choices among actors.

Regarding the exogenous control variables, results are significant for the activity (i.e., centrality) of actors in the collaboration network. Well-connected actors are less likely than expected by chance to co-reject policy instruments. There is no compelling evidence for shared instrument preferences when actors are geographically close to each other. Similarly to collaboration, this control variable models the proximity between actors. Geographical proximity, however, does not considerably impact actors' interdependent choices. Results for competence levels (non-adjacent refers to local vs. national level) are not significant. Actors of adjacent levels do not tend to prefer similar policy instruments. The endogenous control variable "actor degree: 0 " indicates that there are more isolates in the actor-instrument network, i.e., actors who do not reject any instrument, than expected by chance in networks of this size.

Figure 6 displays endogenous goodness of fit diagnostics for our Model 2, which illustrate that we capture the endogenous properties of the network very well. The six panels show common auxiliary network statistics in the observed network (the black lines) and in 500 simulations from the estimated model (the gray boxplots). As the boxplot medians are usually very close to the observed statistics, we seem to have properly captured network dependence.

Figure 7 shows receiver-operating characteristic (ROC) curves (red curve from bottom left to top right) and precision-recall curves (blue curve from top left to bottom right), with the light-shaded curves representing a null model for comparison. Both curves indicate a much better model fit in terms of classification performance of dyads than the null model, which means that the model has quite some explanatory value. The MCMC diagnostics (not reported here) indicate convergence, with a slight but yet unproblematic skewness for the isolates term. 
Table 2: Results for the bipartite ERGM with standard errors in parentheses.

\begin{tabular}{|c|c|c|c|}
\hline & Hypothesis & Model 1 & Model 2 \\
\hline \multicolumn{4}{|l|}{ Endogenous controls } \\
\hline \multirow[t]{2}{*}{ Edges } & control & $-2.83^{* * *}$ & $-2.93^{* * *}$ \\
\hline & & $(0.32)$ & $(0.31)$ \\
\hline \multirow[t]{2}{*}{ Actor degree: 0} & control & 1.20 & $1.45^{*}$ \\
\hline & & $(0.76)$ & $(0.65)$ \\
\hline \multirow[t]{2}{*}{ Two-stars (centered on policy instruments) } & control & $-0.21^{* *}$ & $-0.21^{* * *}$ \\
\hline & & $(0.07)$ & $(0.06)$ \\
\hline \multirow[t]{2}{*}{ Non-edgewise shared partners (fixed at 2.0) } & control & $0.38^{* * *}$ & 0.38 \\
\hline & & $(0.06)$ & $(0.06)$ \\
\hline \multicolumn{4}{|l|}{ Exogenous controls } \\
\hline \multirow[t]{2}{*}{ Centrality in the collaboration network } & control & -0.07 & -0.06 \\
\hline & & $(0.03)$ & $(0.03)$ \\
\hline \multirow[t]{2}{*}{ Competence level: non-adjacent } & control & 0.00 & 0.02 \\
\hline & & $(0.08)$ & $(0.08)$ \\
\hline \multicolumn{4}{|l|}{ Policy objectives } \\
\hline \multirow[t]{2}{*}{ Similarity of objectives } & $\mathrm{H} 1 \mathrm{a}$ & & 0.06 \\
\hline & & & $(0.10)$ \\
\hline \multirow[t]{2}{*}{ Agenda priorities: structural similarity } & $\mathrm{H} 1 \mathrm{~b}$ & 0.10 & 0.04 \\
\hline & & $(0.09)$ & $(0.12)$ \\
\hline \multirow{2}{*}{ Actor type: Water/environment vs. } & $\mathrm{H} 1 \mathrm{c}$ & $-0.63^{* *}$ & -0.56 \\
\hline & & $(0.22)$ & $(0.23)$ \\
\hline \multicolumn{4}{|l|}{ Interconnectedness } \\
\hline \multirow[t]{2}{*}{ Collaboration } & $\mathrm{H} 2 \mathrm{a}$ & $0.27^{*}$ & $0.30^{*}$ \\
\hline & & $(0.13)$ & $(0.13)$ \\
\hline \multirow[t]{2}{*}{ Collaboration: structural similarity } & $\mathrm{H} 2 \mathrm{~b}$ & 0.01 & -0.00 \\
\hline & & $(0.02)$ & $(0.03)$ \\
\hline \multirow[t]{2}{*}{ Co-membership in water basin organizations } & $\mathrm{H} 2 \mathrm{c}$ & -0.10 & -0.09 \\
\hline & & $(0.33)$ & $(0.33)$ \\
\hline Number of actors & & 32 & 31 \\
\hline Number of instruments & & 15 & 15 \\
\hline Number of dyads & & 480 & 465 \\
\hline Number of edges & & 101 & 97 \\
\hline AUC Precision-Recall & & 0.54 & 0.53 \\
\hline AUC Precision-Recall random graph & & 0.20 & 0.22 \\
\hline
\end{tabular}


Dyad-wise shared partners

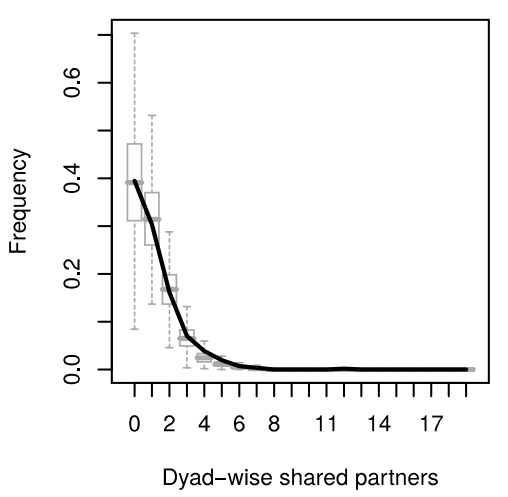

k-star

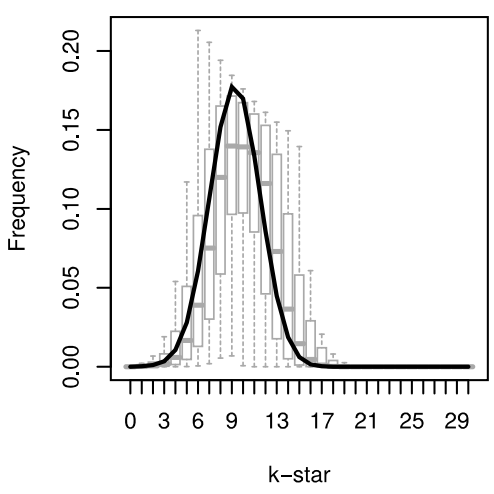

Non-edge-wise shared partners

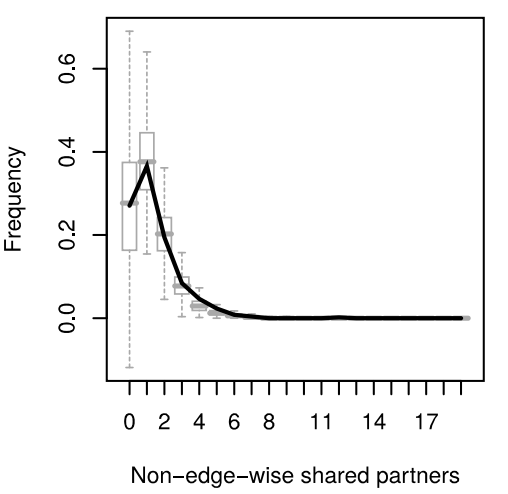

Geodesic distances

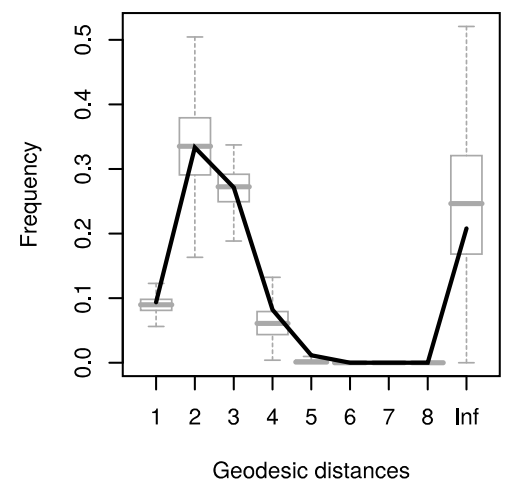

Degree

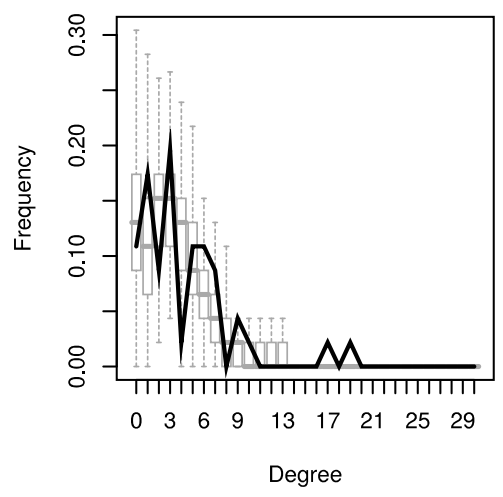

Triad census

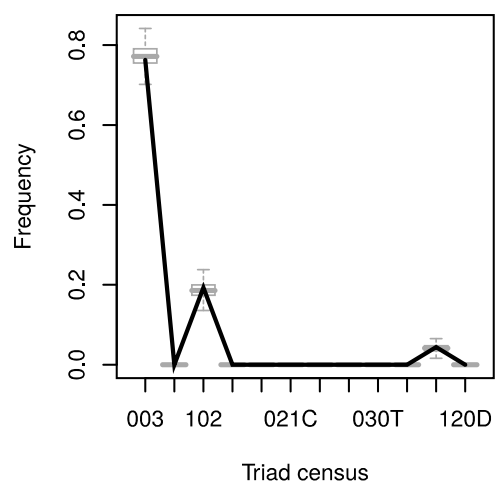

Figure 6: Endogenous goodness of fit diagnostics for Model 2. (Model 1 is very similar.)

Note: The six panels show common auxiliary network statistics in the observed network (the black lines) and in 500 simulations from the estimated model (the gray boxplots). The close match between the observed network and the simulations based on the model indicate that the model reproduces key features of the network topology adequately, which means that any omitted variable bias due to unmodeled dependence is largely eliminated (cf. Cranmer et al. 2017). The diagram was created using the xergm package (Leifeld et al. 2018).

Online Appendix 2 contains additional model specifications, which rule out the possibility of multicollinearity (Model 2a), consider alternative explanations like clustering of instruments into overarching instrument categories (Models 2b-2e), the special role of decision-makers like governmental actors and parties and their instrument choices (Model 2f), geographical clustering of policy preferences (Model $2 \mathrm{~g}$ ), actor type homophily as a variable that may cluster actors' preferences (Model 2h), and assess the outcomes of a different estimation technique (Model 2i). In short, none of these qualifications changes the main substantive results presented here, with the possible exception of clustering instrument preferences by overarching categories: If one assumes that every instrument is an indicator of a more general policy approach and if one controls for clustering within these approaches (regulatory, market-based, and information-based, see Table 1), then in this one model specification, interconnectedness drops out of significance because the additional clustering takes away some of the residual variance that can be modeled using our main hypotheses. Conflict lines, however, still remain significant predictors of instrument preferences. 


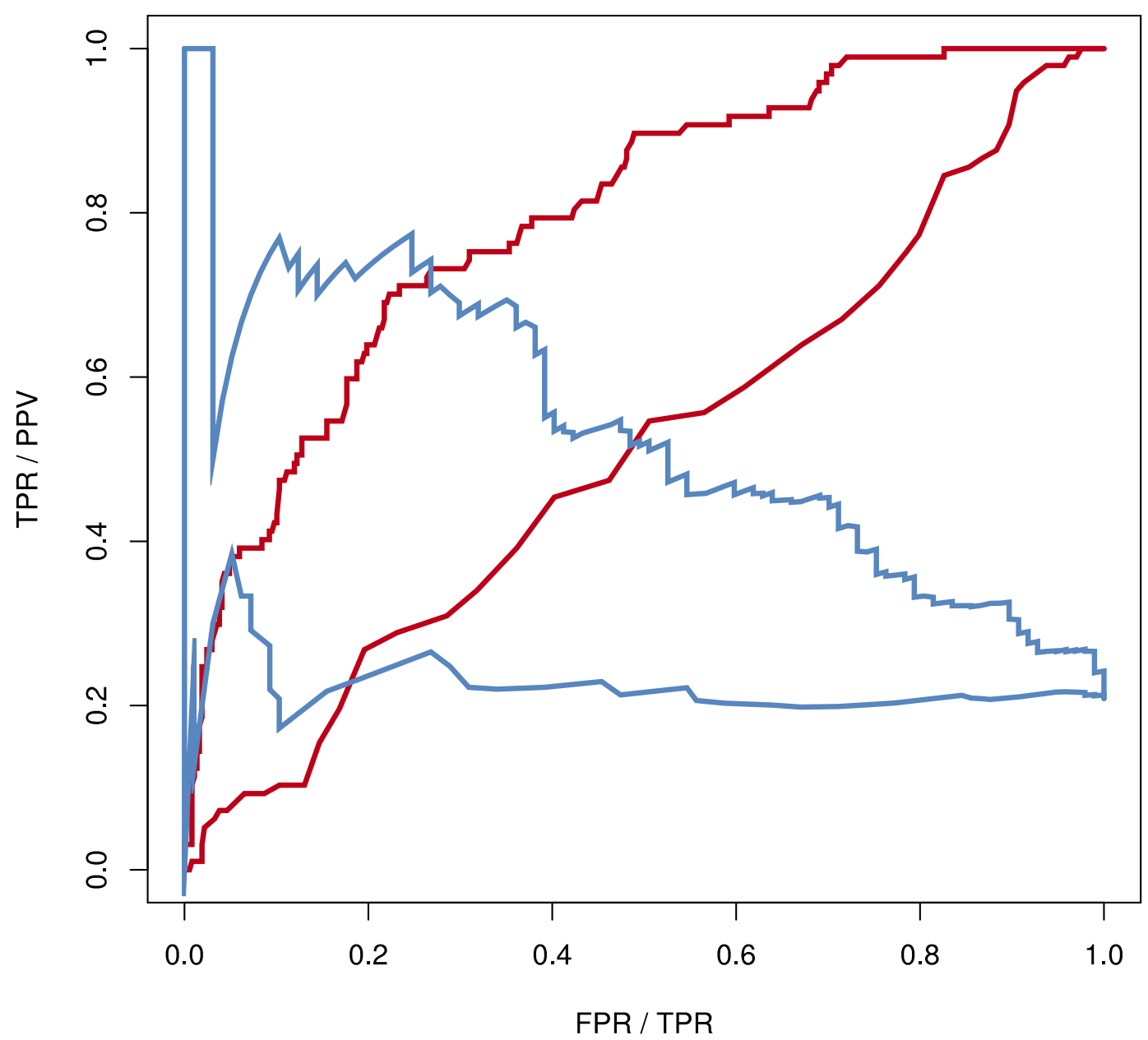

Figure 7: Within-sample predictive fit. Receiver-operating characteristic (ROC) curves (red curve from bottom left to top right) and precision-recall (PR) curves (blue curve from top left to bottom right), with the light-shaded curves representing a null model for comparison.

Note: ROC and PR are two alternative measures for model fit that indicate to which extent simulations based on the model can reproduce the location of ties in the network (Leifeld et al. 2018). ROC curves trending towards the upper left corner indicate a good within-sample predictive performance of the model ( $=$ high true positive rate and low false positive rate of the simulated networks in terms of tie prediction). PR curves trending towards the upper right corner indicate a good within-sample predictive performance ( $=$ high precision and high recall of the rejection ties in the observed network). Both curves show a large difference between a null model and Model 2.

\section{Discussion and Conclusion}

In order to understand how policy actors strategically position themselves in water protection given the choices of others, we studied actors' preferences for policy instruments as an interdependent system. We modeled the social interdependencies by conceptualizing policy preferences as a two-mode network of actors and their instrument preferences for pollution reduction measures. By fitting an ERGM, we studied the mechanisms behind the formation of policy preferences. Thereby the article contributes to the literatures on collective decisionmaking, policy preferences, and networks. Our first contribution is that we find evidence for network interdependencies between actors' policy preferences through considerable clustering in the actor-instrument network. The two-mode network lens offers a particularly sound approach to the study of preference formation as it has the ability to capture the complex and interdependent system of actors and their preferences. 
The network dependence at work might take the form of diffusion of preferences among actors. However, causality cannot be disentangled in a cross-sectional study (and usually not with temporal data unless they are nearly continuously observed; see Malang et al. 2018). Consequently, it may be plausible that factors like collaboration are not solely the cause, but also a consequence of similar preferences. Future research should adopt a fine-grained longitudinal perspective on instrument preferences in order to examine the temporal pattern of policy instrument diffusion and separate it from social selection. To achieve this goal, either advances in the temporal measurement of organizational preferences or experimental design will be necessary.

Our second contribution is that we empirically studied the relationship between individual-level and group-level foundations of preference formation. On the individual level, we considered actors' attributes in the form of shared objectives (as in H1), and on the group level, we considered relational effects trough collaboration (H2). With regard to relational effects, we observe that interconnected actors, who collaborate with each other, tend to exhibit interdependent policy preferences (confirmation of Hypothesis 2). Pertaining to attribute-based effects, we find that instrument preferences are partly conditional on others who exhibit similar functional roles and responsibilities (partial confirmation of $\mathrm{H1}$ ). This is a form of political homophily or heterophily (McPherson, Smith-Lovin, and Cook 2001). However, we do not find any evidence for political homophily in the form of shared policy objectives or agenda priorities. Homophily effects in the form of shared beliefs are well-documented (Calanni et al. 2014, Gerber, Henry, and Lubell 2013, Ingold and Fischer 2014, Zafonte and Sabatier 1998). The cited studies find evidence that actors who share beliefs tend to collaborate, but they do not investigate the consequences of collaboration on preference formation. Our results contribute to closing this gap by analyzing both the role of underlying objectives and collaboration on preference formation. Findings indicate that actors' objectives defined by their functional roles (as operationalized by H1c), and actors' interconnectedness (as operationalized by H2a), play a role in shaping the collective preferences of a nascent policy domain. As alternative operationalizations of interconnectedness $(\mathrm{H} 2 \mathrm{~b}-\mathrm{c})$ and policy objectives $(\mathrm{H} 1 \mathrm{a}-\mathrm{b})$ did not yield significant results, we conclude that those variables operate through specific mechanisms. With our study, we contribute to conceptual precision around these mechanisms.

Policy decisions are not merely in the hands of selected public officials or authorities, but take place in a governance structure involving different public and private actors. In such complex settings, the agreement upon what instruments to select and which ones to reject represents an important precondition to successfully produce policy outputs and overcome collective action problems. Future research should investigate in a longitudinal design whether actors use their collaboration ties as a mechanism of preference coordination and compromise settlement. If this were not the case, i.e., if actors formed their instrument preferences on the basis of their own fixed objectives only, producing policy outputs would be very difficult where actors with conflicting objectives participate in decision-making. But, our results indicate that not only functional roles, but also interconnectedness matters for the formation of policy preferences. Hence, actors can overcome their differences and successfully agree on policies when they initiate connections and exchanges during policy negotiations. In summary, where policy preferences depend both on fixed roles (as indicated by H1c) and collaboration (H2a), policymaking is both a function of who participates in policymaking and a matter of negotiation and, hence, compromise-seeking.

Finally, our results indicate that deliberation, if it matters in policy instrument preference formation, is constrained to direct collaboration between actors rather than international forums. Future research should seek to evaluate the precise relationship between coordination through 
policy forums and direct collaboration between actors and the consequences for preference formation.

\section{References}

Berardo, Ramiro. 2014. "Bridging and Bonding Capital in Two-Mode Collaboration Networks." Policy Studies Journal 42 (2):197-225.

Bodin, Ö., Crona, B.I. . 2009. "The role of social networks in natural resource governance: What relational patterns make a difference?" Global Environmental Change 19:366-374.

Bodin, Örjan, and Christina Prell, eds. 2011. Social Networks and Natural Resource Management. Uncovering the Social Fabric of Environmental Governance. Cambridge: Cambridge University Press.

Börzel, Tanja. 1998. "Organizing Babylon. On the Difierent Conceptions of Policy Networks." Public Administration 76:253-273.

Bressers, Hans, Dave Huitema, and Stefan Kuks. 1995. "Policy Networks in Dutch Water Policy." In Networks for Water Policy. A Comparative Perspective, edited by Hans Bressers, Laurence O'Toole and Jeremy Richardson, 24-51. London: Frank Cass.

Bressers, Hans, and Laurence O’Toole. 1998. "The Selection of Policy Instruments: A NetworkBased Perspective." Journal of Public Policy 18 (3):213-239.

Bressers, Hans, and Laurence O’Toole. 2005. "Instrument selection and implementation in a networked context." In Designing government: From instruments to governance, edited by Pearl Eliadis, Margaret Hill and Michael Howlett, 132-153. Montreal, Kingston: McGill-Queen's University Press.

Bressers, Hans, Laurence O'Toole, and Jeremy Richardson, eds. 1995. Networks for Water Policy: A Comparative Perspective. London: Frank Cass.

Briatte, François. 2016. "Network Patterns of Legislative Collaboration in Twenty Parliaments." Network Science 4 (2):266-271. doi: 10.1017/nws.2015.31.

Calanni, John C., Saba N. Siddiki, Christopher M. Weible, and William D. Leach. 2014. "Explaining Coordination in Collaborative Partnerships and Clarifying the Scope of the Belief Homophily Hypothesis." Journal of Public Administration Research and Theory. doi: 10.1093/jopart/mut080.

Cranmer, Skyler, and Bruce Desmarais. 2011. "Inferential Network Analysis with Exponential Random Graph Models." Political Analysis 19:66-86.

Cranmer, Skyler J., Philip Leifeld, Scott D. McClurg, and Meredith Rolfe. 2017. "Navigating the Range of Statistical Tools for Inferential Network Analysis." American Journal of Political Science 61 (1):237-251.

Fischer, Manuel, and Philip Leifeld. 2015. "Policy Forums: Why Do they Exist and What are they Used for?" Policy Sciences 48 (3):363-382.

Gerber, Elisabeth, Adam Douglas Henry, and Mark Lubell. 2013. "Political Homophily and Collaboration in Regional Planning Networks." American Journal of Political Science 57 (3):598-610.

Granovetter, Mark. 1985. "Economic Action and Social Structure: The Problem of Embeddedness." American Journal of Sociology 91:481-510.

Granovetter, Mark. 1992. "Economic Institutions as Social Construction: A Framework of Analysis." Acta Sociologica 35:3-11.

Harward, Brian M., and Kenneth W. Moffett. 2010. "The Calculus of Cosponsorship in the U.S. Senate." Legislative Studies Quarterly 35 (1):117-143. 
Hollender, Juliane, Heinz Singer, and Christa McArdell. 2008. "Polar Organic Micropollutants In The Water Cycle." In Dangerous Pollutants (Xenobiotics) in Urban Water Cycle, edited by Petr Hlavinek, Ongjen Bonacci, Jiri Marsalek and Ivana Mahrikova, 103-116. Dodrecht: Springer.

Howlett, Michael. 2009. "Governance modes, policy regimes and operational plans: A multi-level nested model of policy instrument choice and policy design." Policy Science 42:73-89.

Howlett, Michael, and M Ramesh. 1995. Studying Public Policy: Policy Cycles and Policy Subsystems. Toronto, New York: Oxford University Press.

Hunter, David. 2007. "Curved exponential family models for social networks." Social Networks 29 (2): 216-230.

Hunter, David, Mark Handcock, Carter Butts, Steven Goodreau, and Martina Morris. 2008. "ergm: A Package to Fit, Simulate and Diagnose Exponential-Family Models for Networks." Journal of Statistical Software 24 (3). doi: 10.18637/jss.v024.i03

Ingold, Karin. 2014. "How involved are they really? A comparative network analysis of the institutional drivers of local actor inclusion." Land Use Policy 39:376-387.

Ingold, Karin, and Manuel Fischer. 2014. "Drivers of collaboration to mitigate climate change: An illustration of Swiss climate policy over 15 years." Global Environmental Change 24:8898.

Ingold, Karin, Frédéric Varone, and Frans Stokman. 2013. "A social network-based approach to assess de facto independence of regulatory agencies." Journal of European Public Policy 20 (10):1464-1481.

Jenkins-Smith, Hank, Carol L. Silva, Kuhika Gupta, and Joseph T. Ripberger. 2014. "Belief System Continuity and Change in Policy Advocacy Coalitions: Using Cultural Theory to Specify Belief Systems, Coalitions, and Sources of Change." Policy Studies Journal 42 (4):484-508. doi: 10.1111/psj.12071.

Jones, Candace, William S. Hesterley, and Stephen P. Borgatti. 1997. "A General Theory of Network Governance: Exchange Conditions and Social Mechanisms." Academy of Management Review 22 (4):911-945.

Kammermann, Lorenz, and Clau Dermont. forthcoming. "Avoiding the Inevitable - Opposition against instruments promoting renewable energy transitions." Energy Research \& Social Science.

Keohane, Nathaniel, Richard Revesz, and Robert Stavins. 1998. "The choice of regulatory instruments in environmental policy." Harvard Environmental Law Review 22 (2):313367.

Knill, Christoph, and Jale Tosun. 2012. Public Policy: A New Introduction. New York: Palgrave Macmillan.

Knoke, David. 1994. "Networks of Elite Structure and Decision Making." In Advances in Social Network Analysis: Research in the Social and Behavioral Sciences, edited by Stanley Wasserman and Joseph Galaskiewicz, 274-95. Thousand Oaks: Sage.

Landry, Réjean, and Frédéric Varone. 2005. "The Choice of Policy Instruments: Confronting the Deductive and the Interactive Approaches." In Designing government. From instruments to governance, edited by F. P. Eliadis, M. M. Hill and M. Howlett, 106-131. Montreal, Kingston: McGill-Queen's University Press.

Lasswell, Harold. 1958. Politics: who gets what, when, how. With postscript (1958). New York: Meridian Books.

Laumann, Edward, Peter Marsden, and David Prensky. 1983. "The Boundary Specification Problem in Network Analysis." In Applied Network Analysis: A Methodological Introduction, edited by Ronald Burt and Michael Minor. Beverly Hills: Sage. 
Leifeld, Philip. 2013. "texreg: Conversion of Statistical Model Output in R to LaTeX and HTML Tables." Journal of Statistical Software (8):24. doi: 10.18637/jss.v055.i08.

Leifeld, Philip, Skyler Cranmer, and Bruce Desmarais. 2017. xergm: Extensions of Exponential Random Graph Models. R package version 1.8.3. https://cran.r-project.org/package=xergm.

Leifeld, Philip, and Volker Schneider. 2012. "Information Exchange in Policy Networks." American Journal of Political Science 56 (3):731-744.

Linder, Stephen, and Guy Peters. 1989. "Instruments of Government: Perceptions and Contexts." Journal of Public Policy 9 (1):35-58.

Lubell, Mark, and Allan Fulton. 2007. "Local Diffusion Networks as Pathways to Sustainable Agriculture." California Agriculture 61 (3): 131-137.

Lubell, Mark, John Scholz, Ramiro Berardo, and Garry Robins. 2012. "Testing Policy Theory with Statistical Models of Networks." Policy Studies Journal 40 (3):351-374.

Malang, Thomas, Laurence Brandenberger, and Philip Leifeld. 2017. "Networks and social influence in European legislative politics." British Journal of Political Science Accepted for Publication.

March, James G., and Johan P. Olsen. 1989. Rediscovering Institutions: The Organizational Basis of Politics. NewYork: Free Press.

Marsden, Peter V. 1981. "Introducing Influence Processes into a System of Collective Decisions." American Journal of Sociology 86 (6):1203-1235.

McPherson, Miller, Lynn Smith-Lovin, and James M. Cook. 2001. "Birds of a Feather: Homophily in Social Networks." Annual Review of Sociology 27:415-444.

Munro, Geoffrey D., and Peter H. Ditto. 1997. "Biased Assimilation, Attitude Polarization, and Affect in Reactions to Stereotype-Relevant Scientific Information." Personality and Social Psychology Bulletin 23 (6):636-653.

Munro, Geoffrey D., Peter H. Ditto, Lisa K. Lockhart, Angela Fagerlin, Mitchell Gready, and Elizabeth Peterson. 2002. "Biased Assimilation of Sociopolitical Arguments: Evaluating the 1996 U.S. Presidential Debate." Basic and Applied Social Psychology 24 (1):15-26.

Newig, Jens, and Oliver Fritsch. 2009. "Environmental governance: participatory, multi-level and effective?" Environmental Policy and Governance 19 (3):197-214.

Olson, Mancur. 1965. The logic of collective action. Cambridge, MA: Harvard University Press.

Ostrom, Elinor, Michael Cox, and Edella Schlager. 2014. "An Assessment of the Institutional Analysis and Development Framework and Introduction of the Social-Ecological Systems Framework." In Theories of the Policy Process, edited by Paul Sabatier and Christopher Weible, 267-306. Boulder, CO: Westview Press.

Pahl-Wostl, Claudia. 2007. "The implications of complexity for integrated resources management." Environmental Modelling \& Software 22 (5):561-569. doi: http://dx.doi.org/10.1016/j.envsoft.2005.12.024.

Robins, Garry, Lorraine Bates, and Philippa Pattison. 2011. "Network Governance and Environmental Management: Conflict and Cooperation." Public Administration 89 (4):1293-1313.

Robins, Garry, Pip Pattison, Yuval Kalish, and Dean Lusher. 2007. "An introduction to exponential random graph $\left(\mathrm{p}^{*}\right)$ models for social networks." Social Networks 29 (2):173191.

Robins, Garry, Tom Snijders, Peng Wang, Mark Handcock, and Philippa Pattison. 2007. "Recent developments in exponential random graph $\left(\mathrm{p}^{*}\right)$ models for social networks." Social Networks 29 (2):192-215.

Sabatier, Paul. 1999. Theories of the Policy Process. Boulder, CA: Westview Press.

Sabatier, Paul, and Hank Jenkins-Smith. 1993. Policy Change and Learning: An Advocacy Coalition Approach. Boulder: Westview Press. 
Sager, Fritz. 2009. "Governance and Coercion." Political Studies 57 (3):537-558.

Sandström, Annika, and Lars Carlsson. 2008. "The Performance of Policy Networks: The Relation between Network Structure and Network Performance." The Policy Studies Journal 36 (4):497-524.

Schneider, Volker. 2014. "Akteurskonstellationen und Netzwerke in der Politikentwicklung." In Lehrbuch der Politikfeldanalyse, edited by Klaus Schubert and Nils Bandelow, 259-288. München: Oldenbourg.

Schwarzenbach, René, Beate Escher, Kathrin Fenner, Thomas Hofstetter, Annette Johnson, Urs Von Gunten, and Bernhard Wehrli. 2006. "The Challenge of Micropollutants in Aquatic Systems." Science 313 (5790):1072-1077.

Varone, Frédéric. 1998. Le choix des instruments des politiques publiques. Une analyse comparée des politiques d'efficience énergétique du Canada, du Danemark, des Etats-Unis, de la Suède et de la Suisse. Bern: Paul Haupt Verlag.

Wang, Peng, Ken Sharpe, Garry L. Robins, and Philippa E. Pattison. 2009. "Exponential Random Graph (p*) Models for Affiliation Networks. Social Networks." 31 (1):12-25.

Wasserman, Stanley, and Philippa Pattison. 1996. "Logit models and logistic regressions for social networks: I. An introduction to Markov graphs and p*." Psychometrika 61:401-425.

Weible, Christopher, Andrew Pattison, and Paul Sabatier. 2010. "Harnessing expert-based information for learning and the sustainable management of complex socio-ecological systems." Environmental Science \& Policy 13 (6):522-534.

Weible, Christopher, and Paul Sabatier. 2005. "Comparing Policy Networks: Marine Protected Areas in California." Policy Studies Journal 33 (2):181-201.

Zafonte, Matthew, and Paul Sabatier. 1998. "Shared Beliefs and Imposed Interdependencies as Determinants of Ally Networks in Overlapping Subsystems." Journal of Theoretical Politics 10 (4):473-505.

Zhang, Yan, A. J. Friend, Amanda L. Traud, Mason A. Porter, James H. Fowler, and Peter J. Mucha. 2008. "Community structure in Congressional cosponsorship networks." Physica A: Statistical Mechanics and its Applications 387 (7):1705-1712. doi: https://doi.org/10.1016/j.physa.2007.11.004. 